\title{
Decisiones, incertidumbre y el cerebro
}

\author{
Paul W. Glimcher. La ciencia de la neuroeconomía. Fondo de Cultura Económica. $1^{\text {ra }}$ edición en \\ español 2009, 389 pp.
}

\author{
David Quebradas ${ }^{1 *}$ \\ 1 Grupo de Investigación Análisis: Mente, Lenguaje y Cognición. \\ Universidad del Valle. Cali, Colombia.
}

\begin{abstract}
"Estos Hombres estarán compuestos, como nosotros, de un alma y un cuerpo; y primero debo describirles el cuerpo; luego, también por separado el alma; y por último debo mostrarles cómo tendrían que unirse e integrarse estas dos naturalezas para constituir a los hombres". L' Homme [El tratado del hombre]. Descartes, 1664.
\end{abstract}

El dualismo instaurado por Descartes no se reduce al dualismo mente-cuerpo mencionado en la cita anterior, sino que, además de la distinción entre una res cogitans (cosa pensante) y una res extensa (cosa extensa), hay otro dualismo que se sigue de este: una división tajante entre los comportamientos simples y deterministas, que podían caer en la red del conocimiento de la física mecánica del siglo XVII, y los comportamientos indeterminados que parecían escapar a una descripción mecanicista, debido a la impredecibilidad de la voluntad, al capricho de la volición, a la mente (res cogitans) interpuesta entre la sensación y la acción. En otras palabras, un dualismo entre comportamientos que podían determinarse a partir de la forma como el sistema nervioso conecta la sensación y la acción, en el que un estímulo sensorial dado produce invariablemente una respuesta motora específica o refleja, y comportamientos en el que la relación entre el estímulo y la respuesta es impredecible.

Esta concepción cartesiana del comportamiento hizo que responder la cuestión de cómo y por qué los seres humanos se comportan como lo hacen no fuera posible desde un modelo científico determinista, siempre y cuando se aceptara que "algo que no puede determinarse como la mente era capaz de dirigir el curso de la acción". Sin embargo, el mayor problema de este marco, que sirvió de referencia para las investigaciones del comportamiento por largos años, y que aún aparece en la estructura

\footnotetext{
* Correspondencia: davqueno@gmail.com . Grupo de Investigación Análisis: Mente, Lenguaje y Cognición. Universidad del Valle, Cali, Colombia.Edificio 386, espacio 3005. Ciudad UniversitariaMeléndez Carrera 100 Con Calle 13 Teléfono: +57 (23) 3212100 extensión 2370

Recibido: 02-11-11. Revisión desde: 20-11-11. Aceptado: 13-12-11
}

de algunas investigaciones actuales, es creer que una idea como el reflejo sirve para explicar el comportamiento y, en su versión más extrema, que el comportamiento complejo pueda ser reducido a un conjunto de reflejos interconectados, como llegó a pensarlo I. P. Pavlov, quien consideró que no había tal cosa como los comportamientos indeterminados.

Pero fue Charles Scott Sherrington, el verdadero precursor de la idea del reflejo tal como se conoce hoy en día, quien propuso que:

"El concepto de reflejo abarca en consecuencia por lo menos tres estructuras diferentes: un órgano efector, esto es, células glandulares o células musculares; una vía nerviosa conductora (o conductor) dirigida hacia ese órgano, y un órgano iniciador o receptor, donde la reacción comienza. En la reacciones que nosotros tenemos que estudiar, el conductor consiste por lo menos en dos células nerviosas, una conectada con receptor y otro con el efector [...] [conviniendo] llamar arco reflejo a toda la cadena de estructuras: receptor, conductor y efector. [Sherrington, 1906]" (p.

82).

Ahora bien, buena parte de la importancia del texto de Paul W. Glimcher reside en: 1) un modo desacostumbrado de atacar el dualismo cartesiano, al enfrentarse a la idea de reflejo heredada de Descartes y no al problema mente-cuerpo, considerando a la vez que del hecho de aceptar la existencia de comportamientos deterministas e indeterministas, producto de la incapacidad de las herramientas matemáticas deterministas para describir toda la complejidad del comportamiento, no se sigue que haya causas del comportamiento físicas y no físicas; 2 ) rechazar la teoría de los reflejos, que de acuerdo al autor no es más que un modelo de la manera como las señales sensoriales originan las respuestas motoras y que no logra explicar los comportamientos complejos e indeterminados, y 3) exponer un monismo indeterminado que, a partir de un cuerpo matemático como la teoría de probabilidad, pueda brindar una nueva alternativa al problema de la relación entre el comportamiento, el cerebro y la mente, en la que se pueda reconocer que hay ciertos aspectos del mundo irreductiblemente inciertos $y$ ocasiones en el que el comportamiento tiene que ser 
impredecible, aceptando de esta manera comportamientos simples y deterministas y comportamientos que realmente serán inciertos y que no solo parecerán serlo (p. 358-360).

Para entender el peso de lo anterior, hay que hacer explícito por qué la teoría del reflejo sherringtoniano no es un buen marco para responder al problema del comportamiento humano y cómo es posible mantener una concepción monista de las causas del comportamiento, es decir, cómo describir y entender las causas del comportamiento específicamente indeterminado sin acudir al uso de explicaciones y entidades no físicas, como era el caso de la mente cartesiana. En relación con el primer punto, el autor señala que en el marco sherringtoniano el sistema nervioso (SN) no tiene otra función sino "conducir estímulos sensoriales hacia neuronas motoras" (p. 98), una concepción del SN pasiva en la que todo se reduce a una función conductora. Idea bastante errada, tal como lo demostró T. Graham Brown, estudiante de Sherrington que, a partir de sus experimentos realizados con gatos -en los que cortaba sistemáticamente todos los nervios sensoriales $y$ motores que se comunicaban con la médula, dejando intacto solo "los nervios motores de una sola de las patas del gato que activaban los dos músculos principales para caminar" (p. 102)-, pudo observar cómo la médula espinal del gato, totalmente privada de cualquier entrada sensorial, era capaz de producir una salida coordinada por más de un minuto.

No obstante, esta reducida idea de la función del SN es solo una pequeña anomalía del paradigma sherringtoniano, la verdadera anomalía es: 1) que los comportamientos simples no son un cadena de reflejos, como los consideraba Sherrington, sino que están organizados alrededor de objetivos bien definidos, 2) "que los reflejos no conectan per se estímulos sensoriales con movimientos; conectan receptores sensoriales con músculos [...], [teniendo presente que] hay condiciones en que la activación de un solo músculo puede producir toda una variedad de movimientos diferentes" (p. 114). Así, de acuerdo con 2), un reflejo no podría estar definido por la producción de un movimiento o la activación de un músculo particular, en la medida en que no hay vía nerviosa única para un determinado movimiento, lo que es un problema para la definición; y en tanto que, como se señala en 1), los comportamiento simples no son un conjunto disperso de reflejos locales e independientes, sino la respuesta del SN que conecta "un acontecimiento del mundo exterior con un movimiento como objetivo" (p.118), el reflejo es un modelo insuficiente para modelar el comportamiento, puesto que no logra capturar esa conexión entre los estímulos externos y el movimiento correcto para responder a las exigencias del medio ambiente, aspecto que, según Paul Weiss, es cardinal en el SN de los vertebrados y para el que ha evolucionado.

En aras de la claridad, lo anterior se resumen en: la teoría sherringtoniana consideraba que el comportamiento era una respuesta de un conjunto determinado de eslabones conectados que respondían a un estímulo externo, sin darse cuenta que un conjunto determinado de eslabones podían llevar a cabo distintos comportamientos, dependiendo de la exigencia del medio ambiente y la capacidad del SN para elegir un movimiento (adaptativo) que se ajustará con mayor precisión para alcanzar el objetivo expuesto.

Para ir más allá de Sherrington y comprender a cabalidad el punto 1) recientemente señalado, hay que cuestionarse acerca del problema de la coordinación motora
(CM) a la que se enfrenta el SN. Como señala el autor, de acuerdo con Bernstein se pueden establecer dos problemas en relación con la $\mathrm{CM}$, el cinemático - teniendo en cuenta la entrada sensorial-, esto es, ¿qué movimiento sugiere dicha entrada o cuál es el movimiento de la articulación a través del espacio que se espera lograr?, y el dinámico - dado el objetivo cinemático-, es decir, ¿cuál es el patrón de la contracción muscular que permitirá cumplir el objetivo, a partir del estado en el que se encuentre la extremidad? (p. 126). Una vez que se ha reflexionado sobre esto es más evidente que cuando el SN resuelve el problema de coordinación lo hace de manera jerárquica y de forma activa, relacionando primero un estímulo sensorial con un movimiento dirigido hacia la consecución de un objetivo y, posteriormente, computando los patrones de fuerza muscular necesarios teniendo en cuenta las condiciones presentes de la extremidad para producir tal movimiento (Ibíd.). Aun así, se puede considerar que lo mencionado adquiere un mayor valor en el momento en que aparece la teoría computacional de David Marr, desde la que, a partir de las teorías matemáticas del procesamiento computacional, se logró arrojar nuevas luces sobre el problema de la relación entre el cerebro y el comportamiento.

Marr, partiendo de una posición metodológica y perspectiva teórica distinta, sugirió que había que entender el objetivo computacional del sistema neurobiológico estudiado, para posteriormente comprender la estructura del sistema físico neurobiológico que iba a lograr tal objetivo (p.155); no se debía seguir aislando un pequeña parte del rompecabezas del SN y luego tratar de construir un teoría acerca de este, sino establecer en primer lugar qué era lo que el SN trataba de hacer con relación al problema del comportamiento, utilizando las herramientas formales de la matemática, y luego preguntarse cómo el SN lograba ese computo u objetivo (p.156). De este modo, estableció que los estudios neurobiológicos deberían realizarse en tres niveles de complejidad, a saber:

1. La teoría computacional -abstracta-, en el que se define cuál es el objetivo de la computación, por qué es la adecuada y cuál es la lógica de la estrategia para llevarla a cabo (p. 159).

2. La representación y algoritmo, en el que se establece cuál es la representación para la entrada y la salida y el algoritmo para la transformación de una a otra, respondiendo a la vez: ¿cómo se puede llevar a la práctica la teoría computacional expuesta? (Ibíd.).

3. La realización del soporte físico, en el que se detalla la arquitectura computacional para saber cómo se pueden realizar físicamente el algoritmo y la representación (Ibíd.).

Pero, pese a lo útil de los señalamientos y derroteros establecidos por Marr, la teoría computacional suscitó preguntas que permanecieron sin respuesta, cuestiones fundamentales que se concentraban en el primer nivel propuesto, como era el caso de determinar a priori los límites conceptuales del sistema que se deseaba estudiar o el tamaño del conjunto de comportamientos que debían constituir el marco de trabajo en el que se alcanzaría un objetivo computacional (p. 161-162), además del caso de las bases empíricas, para comprobar que la evolución "llevaba necesariamente a los sistemas biológicos hacia el logro eficiente de los objetivos computacionales definidos teóricamente" ( $p$. 162). 
A todo esto, cabe señalar que después de que se reconoció que el SN podía ser entendido como un sistema dirigido a conseguir objetivos, la teoría computacional de Marr tuvo que complementarse con la teoría evolutiva para especificar los objetivos del comportamiento, trabajo que aún faltaba por hacer. Así, si era cierto que el objetivo del comportamiento, desde una teoría evolutiva, era elegir correctamente el curso de acción que maximice la supervivencia del código genético del organismo, el objetivo fundamental del SN debería ser la selección y ejecución de comportamientos adaptativos, que se podría conseguir a partir del uso de la información sensorial y el conocimiento almacenado acerca de la estructura del mundo.

Hasta aquí todo aparenta estar resuelto, pero para desdicha o fortuna de cualquier empresa científica que gravita alrededor del problema de la relación entre el cerebro y el comportamiento, el mundo en el que habitan los organismos vivos no es un mundo lleno de certezas y que pueda determinarse por completo, por el contrario es un mundo incierto, por lo menos en tanto que el conocimiento acerca de este es incompleto, lo que hace que la identificación de la respuesta óptima se ciertamente difícil. De este modo, cualquier herramienta determinista se bate en retirada, dejando entrever que el mayor reto que enfrenta el SN es "seleccionar una respuesta motora (para tomar una decisión) que aumente al máximo la capacidad evolutiva en condiciones de incertidumbre" (p.196). Comprender esto último es el objetivo de la Neuroeconomía, que comienza a incorporar la teoría de las probabilidades en los enfoques para entender la relación entre el comportamiento y el cerebro, con el fin de saber más acerca de la toma de decisiones que, en un nivel global, puede ser caracterizada como la función del sistema nervioso (p. 194).

Esta nueva ciencia, la Neuroeconomía, es la síntesis de la economía, las neurociencias y la biología, un diálogo interdisciplinario que: 1) ha de basarse en la economía (un cuerpo matemático) para describir los comportamientos individuales, 2) deberá usar las herramientas fisiológicas del laboratorio del cerebro para estudiar los módulos neurales que realizan los cómputos (todos o algunos) requeridos para los comportamientos de interés, y 3) tendrá que buscar un explicación en el nivel celular del modo como se llevan a cabo dichos cómputos (p. 342). ¿Cómo lograr esto? Las respuestas, se encuentran en la segunda parte del libro, en la que el autor, Paul Glimcher, presenta de manera extraordinaria: la teoría de la probabilidad, ante todo las matemáticas económicas de Bayes y la teoría de juegos, en la que resaltan figuras como Von Neumann y John Nash, con el objetivo de elaborar una teoría del problema que un ambiente incierto le plantea al SN; los experimentos fisiológicos utilizados para identificar los módulos computacionales que consiguen los objetivos definidos, en los que se subraya la importancia de la corteza parietal posterior 0 , como se conocían anteriormente, corteza lateral intraparietal LIP- (específicamente área 7), y ciertas hipótesis de cómo neuronas de esta región del cerebro se activan en procesos que se relacionan con la codificación de la utilidad esperada de un movimiento relativo a otro movimiento posible (p. 333). Señalando, al finalizar el texto, las implicaciones filosóficas de la actual empresa que apenas comienza, y que parece ofrecer un enfoque monista para relacionar el comportamiento, el cerebro y la mente, sin necesidad de acudir al fantasma en la máquina, en otras palabras sin tener que sin tener que aceptar una fuerza no física que gobierne el comportamiento, solo por el hecho de parecer o ser indeterminado.

No sobra decir que hubiese sido una buena decisión dedicarle mucho más espacio a la segunda parte del libro, pero teniendo en cuenta que no siempre actuamos de manera óptima, que elegir en un mundo incierto no es tarea sencilla, el presente texto solo se concentró en la primera parte del libro, claro está, sin perder el objetivo de esto, que no fue otro que hacer un tránsito rápido de los problemas que los lectores encontrarán y tendrán que entender antes de introducirse en el problema fuerte del libro: Decisiones, incertidumbre y el cerebro, antes de sumergirse de lleno en la ciencia de la Neuroeconomía, que sin duda alguna será un espacio de un alto nivel de reflexión para lectores no expertos, pero también, para aquellos que ya han transitado un largo camino en la comprensión de la relación entre el cerebro y comportamiento, con el afán de entender cómo un sistema físico e indeterminado, como el ser humano, toma de decisiones óptimas en un mundo que apenas empieza a conocer. Sin olvidar que el mismo ser humano hace parte de ese mundo que permanece incierto e indeterminado, quizá por sus propias limitaciones epistemológicas, quizá porque sea la mejor estrategia cuando un ser humano se enfrenta con un competidor semejante. 